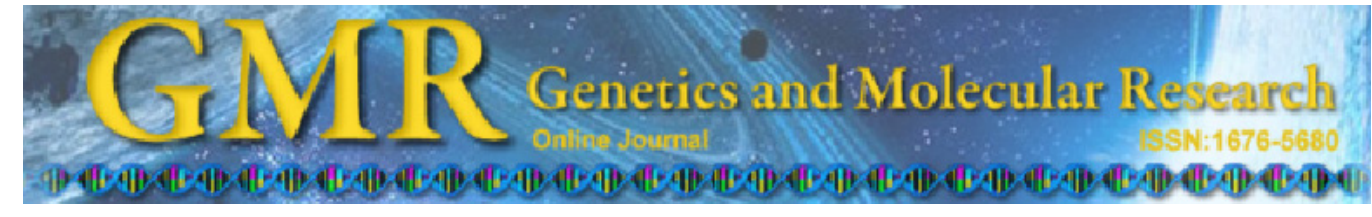

\title{
Comparative fusion expression of maizeSINAT5 in two different strains of Escherichia coli
}

\author{
A. Gholizadeh \\ Department of Molecular Biotechnology, \\ Research Institute for Fundamental Sciences, \\ University of Tabriz, Tabriz, Iran \\ Corresponding author: A. Gholizadeh \\ E-mail: aghz_bioch@yahoo.co.in
}

Genet. Mol. Res. 11 (3): 2760-2768 (2012)

Received August 8, 2011

Accepted June 12, 2012

Published August 24, 2012

DOI http://dx.doi.org/10.4238/2012.August.24.1

\begin{abstract}
SINAT5 is a plant E3 ligase that regulates auxin signaling and root morphogenesis by ubiquitination of the NAC1 protein. Consequently, it may be a putative regulator of aspects of plant development cycles that are controlled by auxin. Efficient production, purification and correctly folded form of this protein are important requirements for functional studies. We produced and quantitatively compared fusion expression of the "maltose binding protein $(\mathrm{mbp})$ maize sinat5" construct in two different strains of Escherichia coli. One-step purification of fused products gave about $33 \mathrm{mg}$ protein/L bacterial cell culture for E. coli TB1 cells and approximately $18 \mathrm{mg}$ protein/L bacterial cell culture for $E$. coli DH5 $\alpha$ cells. Continuous expression of the fused product and similarity of growth patterns were observed in both cultures.
\end{abstract}

Key words: Escherichia coli; E3 ligase; Maltose; Proteosome; Ubiquitin 


\section{INTRODUCTION}

One of the key pathways of post-translational regulation of the levels of specific proteins in eukaryotic cells is the ubiquitin-dependent proteolytic cascade. In this cascade, ubiquitin, a small 76-residue protein is specifically bound to a lysine residue of a target protein directing the tagged protein to be degraded through a 26S proteosomal complex (Smalle and Vierstra, 2004; Moon et al., 2004; Mazzucotelli et al., 2006). The discovery of the ubiquitindependent proteolytic cascade has revolutionized the concept of intracellular protein degradation process in eukaryotes. Over the past few years, the main regulatory functions of protein ubiquitination in various cellular processes such as cell cycle progression, protein trafficking, and signaling pathways has been well described in mammals (Hershko and Ciechanover, 1998; Ciechanover, 1998).

Attachment of a ubiquitin molecule to the target protein is mediated by a 3-step enzymatic mechanism. The first step involves an ATP-dependent attachment of a ubiquitin molecule to the ubiquitin-activating enzyme (E1) through the formation of a high-energy thio-ester bond between the C-terminus of ubiquitin and a cysteine within the E1. In the next step, the ubiquitin molecule is transferred from the E1 enzyme to a cysteine residue in a ubiquitinconjugating enzyme (E2). The last step of the conjugation process involves the transfer of ubiquitin to the target protein via the ubiquitin-protein ligase (E3). A stable isopeptide bond is formed between the carboxyl terminus of ubiquitin and the $\varepsilon$-amino of the lysine residue on the target protein. Ubiquitination can be efficiently modified by multiubiquitin chain assembly factors (E4) that transfer additional ubiquitin moieties (Koegl et al., 1999; Moon et al., 2004).

E3 ubiquitin-protein ligases are the essential determinants of specificity in the substrate conjugation process. They are responsible for target protein recognition and degradation (Su et al., 2006). Currently, E3 ligases are classified into 2 major categories: human E60associated protein (HECT)-type ligases that directly transfer the ubiquitin tag to the substrate (Huibregtse et al., 1995) and the really interesting new gene (RING) or adaptor types that recruit both protein substrate and E2 enzyme to a multi-protein complex (Freemont et al., 1991; Lorick et al., 1999; Pickart, 2001). Both HECT and RING types of E3 ligases have been well characterized with regard to their biological functions in mammalians. Different types of E3 ligases are widely used in mammals (Bates and Vierstra, 1999; Kosarev et al., 2002; Downes et al., 2003; Mazzucotelli et al., 2006).

Recent genomic, transcriptomic and proteomic analyses have shown that over 5\% of Arabidopsis functional genome encode proteins that are homologous to the components of the ubiquitin proteolytic system in mammals (Bachmair et al., 2001; Smalle and Vierstra, 2004; Moon et al., 2004). Approximately $90 \%$ of this gene set encode for different types of E3 ligases. In Arabidopsis plant, this proteolytic system was found to significantly contribute to the growth and developmental processes (Hellmann and Estelle, 2002). Among plant E3 ligases, SINAT5 is one of the well-studied and important enzymes. Arabidopsis SINAT5 has been reported to act as an attenuator of auxin response in root morphogenesis (Xie et al., 2002; Mazzucotelli et al., 2006). Because of its regulatory activity toward auxin, SINAT5 has been thought to control several aspects of plant development by attenuating auxin signals.

Because of the commercial importance of the maize plant, there is a significant interest in understanding its genomic sequence and identifying the biological functions of its encoded genes. There is enormous information on the phenotypic descriptions, disease effects, and 
resistance in this plant. This information can be synergistically integrated with well-defined genes at the transcriptional and functional levels (Alexandrov et al., 2009).

Currently, various E3 ubiquitin protein ligase genes have been identified by maize genome annotation processes or derived from its large-scale cDNA sequencing projects. Among these genes, sinat 5 encoding the structural homologs of Arabidopsis sinat 5 was one of the frequently reported sequences that have been derived from the maize cDNA population. However, there is no report on the biological structures and functions of maize SINAT5. The important requirement for conducting such studies is the high-level production and purification of the correctly folded protein. Maltose-binding fusion protein production and purification system has previously been used for the functional analysis of Arabidopsis SINAT5 enzyme (Xie et al., 2002).

In this study, we produced and compared the expression level of maize SINAT5 as a part of the maltose-binding fusion protein in 2 different strains of Escherichia coli.

\section{MATERIAL AND METHODS}

\section{Materials}

Zea mays L. seeds were obtained from Dr. Bahram Baghban Kohnehrouz (Department of Plant Breeding and Biotechnology, University of Tabriz). E. coli strain DH5 $\alpha$ was provided by Dr. Bahram Baghban Kohnehrouz. E. coli strain TB1 and pMALc2X vector for bacterial transformation, recombinant vector construction, and protein expression studies were supplied in the Protein Fusion and Purification System kit (Cat. No. E8000S; New England, Bio Lab.). Plasmid vector pGEM-T easy used for polymerase chain reaction (PCR) product cloning was from our laboratory stock. The DNA Extraction Kit (Cat. No. K0513; CinnaGen, Fermentas) was used for the purification of the restricted fragment from the agarose gel. Restriction enzymes EcoRI and BamHI used in the cloning procedure were from CinnaGen Company. All the other chemicals used in this research were of molecular biology grade.

\section{Cloning of SINAT5 cDNA}

In order to clone sinat5 cDNA from the root tissues of the maize plant, reverse transcriptase (RT)-PCR method was used. For total RNA isolation, about $0.2 \mathrm{~g}$ root material was fine powdered using liquid $\mathrm{N}_{2}$, and $2 \mathrm{~mL}$ Trizol reagent was added to homogenize the powder at room temperature. Next, $200 \mu \mathrm{L}$ chloroform was added to the mixture, mixed for $15 \mathrm{~s}$, incubated on ice for $5 \mathrm{~min}$, and centrifuged at 13,000 $\mathrm{g}$ for $15 \mathrm{~min}$. The upper phase was transferred to another tube, and RNA was precipitated using an equal volume of isopropanol. The pellet was washed in $1 \mathrm{~mL} \mathrm{75 \%} \mathrm{ethanol,} \mathrm{dried} \mathrm{at} \mathrm{room} \mathrm{temperature,} \mathrm{and} \mathrm{dissolved} \mathrm{in}$ $30 \mu \mathrm{L}$ RNase-free water. Poly $\left(\mathrm{A}^{+}\right)$RNA was purified from the total RNA by using oligo dTcolumns, according to the manufacturer protocol. Specific primers used for the amplification were designed based on the already reported sinat 5 cDNA from maize plant (accession No. EU955347). The following primer set containing EcoRI and HindIII restriction sites was designed using the Primer3 software (http://www.primer3plus.com/web_0.4.0/input.htm): forward: 5'-aatggaattccaggaaatgctggatgc-3'; reverse: 5'-tcacggatcctcactccttccagatcc-3'.

The RT-PCR was performed using one-step AcessQuick ${ }^{\mathrm{TM}}$ RT-PCR System (Cat. No. 
A1701; Promega). Aproximately $0.5 \mu \mathrm{g}$ of each mRNA sample was mixed with $2 \mathrm{X} 25 \mu \mathrm{L}$ Master Mix and $1 \mu \mathrm{L}$ primer set. The mixture was adjusted to a final volume of $50 \mu \mathrm{L}$ using nuclease-free water. The reaction mixture was incubated at $45^{\circ} \mathrm{C}$ for $45 \mathrm{~min}$ and subjected to PCR cycling. PCR was carried out after a pre-denaturation stage at $95^{\circ} \mathrm{C}$ for $3 \mathrm{~min}$, followed by 25 cycles of 1 min denaturation at $95^{\circ} \mathrm{C}$, annealing for $1.5 \mathrm{~min}$ at $55^{\circ} \mathrm{C}$, extension for $2 \mathrm{~min}$ at $72^{\circ} \mathrm{C}$, and a final extension for $10 \mathrm{~min}$ at $72^{\circ} \mathrm{C}$. The amplified products were then extracted from the agarose gel, and cloned in pGEM-T easy cloning vector (Ausubel et al., 1991). The cloned fragments were sequenced at the Microsynth DNA Sequencing Center, Switzerland.

The nucleotide sequence of the isolated cDNA was analyzed by using the Basic Local Alignment Search Tool (BLAST) at http://www.ncbi.nlm.nih.gov/.

\section{Expression of the sinat 5 gene as fused product}

The RT-PCR amplification product after agarose gel purification step was digested with EcoRI and BamHI restriction enzymes, run on 1\% agarose gel, extracted and purified from the gel, and ligated into the pMALc2X expression vector, which had already been linearized at the EcoRI and BamHI sites within the multiple cloning region. The ligation mixture was separately transferred to competent E. coli TB1 and DH5 $\alpha$ cells. For the preparation of competent cells, bacterial cells were grown in Luria Bertani (LB) media. When the $\mathrm{OD}_{600}$ reached 0.4, the cells were kept in ice for $15 \mathrm{~min}$, centrifuged at $3500 \mathrm{rpm}$ for $10 \mathrm{~min}$ at $4{ }^{\circ} \mathrm{C}$, and washed with $10 \mathrm{~mL} 100 \mathrm{mM} \mathrm{CaCl}_{2}$. Subsequently, they were centrifuged at 5000 rpm for $10 \mathrm{~min}$, resuspended in $2 \mathrm{~mL}$ chilled $50 \mathrm{mM} \mathrm{CaCl}_{2}$, and kept in ice for $12 \mathrm{~h}$. For the transformation of bacterial cells, the ligation reaction was mixed with $25 \mu \mathrm{L}$ competent cells, incubated on ice for $5 \mathrm{~min}$, heated to $42^{\circ} \mathrm{C}$ for $2 \mathrm{~min}$, and incubated at $37^{\circ} \mathrm{C}$ for 20 min after addition of $0.1 \mathrm{~mL}$ LB medium. The transformed cells were plated on LB medium (supplemented with Amp and $\mathrm{X}$-gal) at $37^{\circ} \mathrm{C}$, and a recombinant clone was selected for gene expression studies.

\section{Extraction and purification of the expressed fusion protein}

In order to extract the fusion proteins from the transformed cells, the test cells were separately grown in $500 \mathrm{~mL}$ rich broth/glucose/Amp. For the induction of fused protein expression, the inducer molecule isopropyl- $\beta$-d-thiogalactopyranoside (IPTG) was added to a final concentration of $0.3 \mathrm{mM}$, and the mixture was incubated for $8 \mathrm{~h}$. The cells were harvested by centrifugation at $4000 \mathrm{~g}$ for $10 \mathrm{~min}$, and the pellet was dissolved in $25 \mathrm{~mL}$ extraction buffer containing $20 \mathrm{mM}$ Tris-Cl, $200 \mathrm{mM} \mathrm{NaCl}, 1 \mathrm{mM}$ ethylenediaminetetraacetic acid (EDTA), 1 $\mathrm{mM}$ azide, and $10 \mathrm{mM} \beta$-mercaptoethanol (BME). The cells were frozen in the same buffer at $-20^{\circ} \mathrm{C}$ overnight and then sonicated in short pulses of $15 \mathrm{~s}$. The sample was centrifuged at $10,000 \mathrm{~g}$ at $4^{\circ} \mathrm{C}$ for $20 \mathrm{~min}$, and the supernatant was used as crude extract.

The fusion protein was purified from the crude extract by affinity column chromatography. A column packed with amylase resin specific for the maltose-binding protein (MBP), which was a part of fused protein, was used. The fusion protein was eluted out from the column by using the column buffer (extraction buffer plus $10 \mathrm{mM}$ maltose). The eluted product was analyzed for its homogeneity by subjecting it to $10 \%$ sodium dodecyl sulfate-polyacrylamide gel electrophoresis (SDS-PAGE) (Laemmli, 1970). 


\section{Assessment of recombinant bacterial growth}

To determine the effects of the expressed fused products on the growth of the recombinant bacteria, the growth of bacteria was assessed by measuring the OD of the cultures at $\mathrm{A}_{600}$ at 1-h time intervals. Bacterial growth curves were plotted for each test culture and compared to each other.

\section{RESULTS AND DISCUSSION}

Besides Arabidopsis, genomic studies have been conducted on E3 ubiquitin ligases of other plants, particularly in species whose genome has been completely sequenced (Schwechheimer and Schwager, 2004). Because of its commercial importance, maize attracts significant interest for sequencing studies that will facilitate its genetic improvement (Alexandrov et al., 2009). Since 2008, several Arabidopsis homologs of E3 ligase genes, expressed sequence tags and full-length cDNA have been predicted in maize and released in universal databases. Among these predicted genes, sinat 5 homolog (accession No. EU955347) is one of the frequently reported sequences. SINAT5 is a single subunit E3 ligase that has been recently found to target NAC1 transcriptional factor for ubiquitination and downregulation of auxin signals in Arabidopsis plant cells (Xie et al., 2002).

The similarity between maize and Arabidopsis sequences was found to be $78 \%$ (Figure 1). On the basis of their high-sequence identity specifically based on the RING domain homologies, their properties and enzymatic activities are believed to be similar. However, most RING domains have been known to exhibit unique structural characteristics beyond primary structures that may affect the specificity of the recruitment of ubiquitin-conjugating enzyme (E2) or substrate recognition process (Kandias et al., 2009).

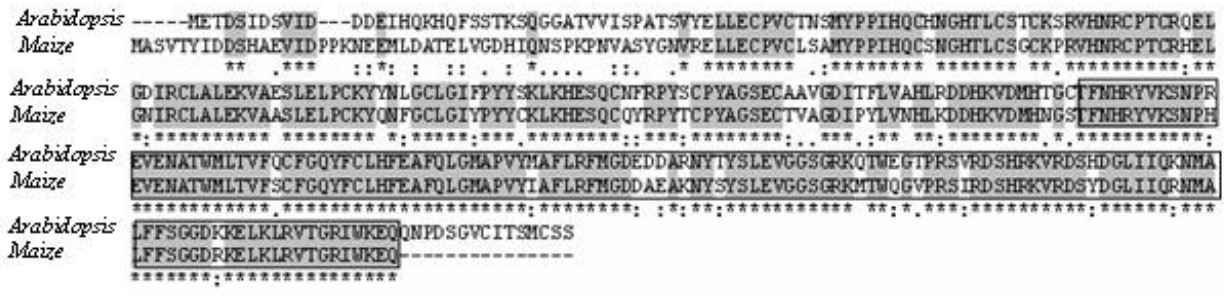

Figure 1. Alignment between maize and Arabidopsis SINAT5. Predicted amino acid sequence of maize SINAT5 (accession No. EU955347) was aligned with the sequence of correspondence protein in Arabidopsis (accession No. AF480944). Sina C-terminal substrate binding domain (towards E2 ubiquitin-conjugating enzyme) was shown inside the box. The alignments were performed by ClustalW.

Of the single subunit RING-type E3 ligases, SINAT5 seems to be an important one, since it may control several aspects of plant development by attenuating auxin signals (Xie et al., 2002). Therefore, further experiments are needed to identify the developmental roles of this protein in the plant system. SINAT5 might be a good biotechnological tool for genetic improvement of auxin-dependent developmental processes in plants.

The important requirement for conducting functional studies of proteins is the efficient production and purification of correctly folded proteins in heterologous systems that 
are mostly bacteria. Among these bacteria, E. coli is a popular system used for the production of foreign proteins in the form of recombinant or fused products (Makrides, 1996; Andersen and Krummen, 2002). Several strategies have been developed to enhance gene expression and posttranslational steps, specifically protein folding in E. coli cells. Of these strategies, fusion tags were originally developed for enhancing protein folding and stability in a native conformation (Terpe, 2006). Fused MBP tags not only provide high level of protein expression because of a strong promoter, but also efficiently enhance the folding and stability of fused proteins. This ensures that the bioactivity of the fused products is minimally affected (Kapust and Waugh, 1999).

MBP tags have already been used for the expression of different types of foreign proteins in E. coli. A previous study reported the expression and purification of Arabidopsis SINAT5 by using MBP tags (Xie et al., 2002). The correct folding of the MBP-Arabidopsis SINAT5 construct and the stability of this fusion protein have facilitated functional studies in vitro.

In the present study, the expression levels of $m b p$-maize sinat 5 construct were determined and compared between 2 different strains of E. coli, TB1 and DH5 $\alpha$. Because of the involvement of the SINAT5 protein in root morphogenesis, the gene was cloned from root tissues grown under normal growth conditions. The cloning was carried out by using RT-PCR with specific primer pairs designed based on the already reported cDNA sequences from different tissues of maize. Analysis of the RT-PCR end-products on 1\% agarose gel revealed a detectable amplified fragment having a molecular size that was consistent to the calculated size for maize putative sinat 5 cDNA. For further confirmation, the amplified cDNA was cloned on pGEM-T easy vector followed by nucleotide sequencing. Analysis of the sequence data revealed that the amplified cDNA was $100 \%$ identical to the already reported sequence. A photograph of the agarose gel and the nucleotide sequence of the amplified product are shown in Figure 2.

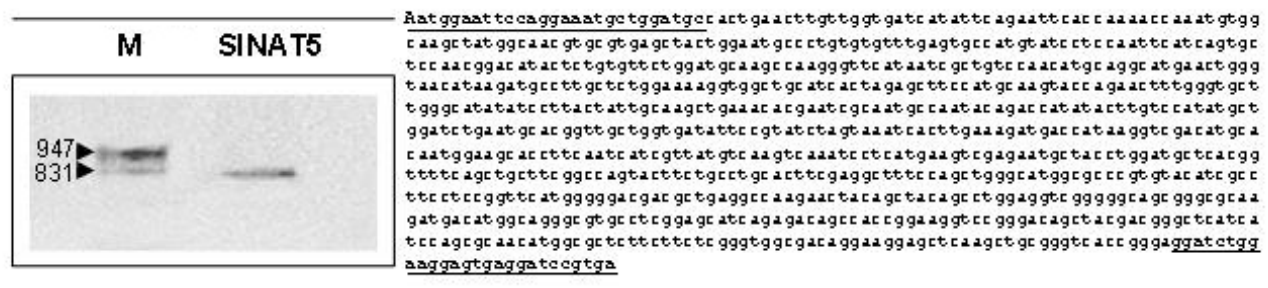

Figure 2. Analysis of RT-PCR end-product from maize roots. RT-PCR was performed using one-step AcessQuick ${ }^{\mathrm{TM}}$ RT-PCR System using the specific primers designed based on the already reported sequence from mixed tissues. To confirm the amplified SINAT5 gene, the amplified fragment was cloned and sequenced. The sequence result and the position of the primers were shown in the figure. Lane $M=E c o$ RI and HindIII double-digested lambda DNA marker.

For protein expression, the amplified cDNA was inserted between EcoRI and HindIII restriction sites of the expression vector pMALc2X, downstream of the MBP sequence to yield fused $m b p$-sinat 5 . The same expression procedure was used for both the strains. The expression of the fused product was induced by IPTG and analyzed in the soluble fraction of the bacterial cultures. SDS-PAGE analysis of the total soluble proteins confirmed the presence of an expressed product with a molecular size of about $72 \mathrm{kDa}$ in both the test cultures (Figure 3). The size of the expressed protein was consistent to the calculated molecular weight for MBPSINAT5 fusion construct, consisting of the MBP $(42,482 \mathrm{kDa})$, the product of 281-amino 
acid residues of cDNA and 6-amino acid residues from the expression vector. Comparison of the relative abundance of the expressed protein on the gels showed that maize SINAT5 was expressed in higher amounts in TB1 cells.

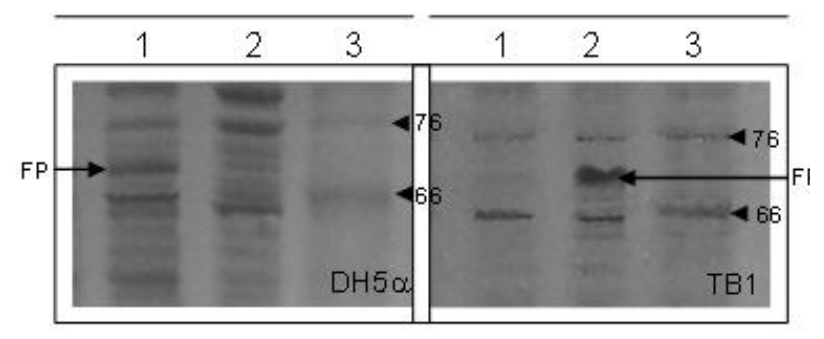

Figure 3. SDS-PAGE analysis of the expressed fused maltose binding protein (MBP)-maize SINAT5. The crude protein of the cultured test cells was extracted separately and the same volume of each sample was analyzed on $10 \%$ polyacrylamide gel as described in Material and Methods. The gels were stained with Coommassie brilliant blue dye. An extra-expressed band corresponding to a 72-kDa protein is observed on both gels. Right: TB1 strain; lane 1 = cells carrying recombinant MBP plasmid; lane $2=$ cells carrying non-recombinant MBP vector; lane $3=$ protein molecular weight marker. Left: DH5 $\alpha$ strain; lane $1=$ cells carrying non-recombinant MBP vector; lane $2=$ cells carrying recombinant MBP plasmid; lane 3 = protein molecular weight marker; $\mathrm{FP}=$ fused protein.

Single-step purification of the fused protein by using MBP affinity chromatography revealed that about $33 \mathrm{mg}$ maize SINAT5 was obtained per liter of bacterial culture for DH5 $\alpha$ cells. This shows a 2:1 ratio of yield between the 2 cell types. Therefore, the TB1 strain is suitable for conducting fusion expression and purification studies of the maize SINAT5 protein.

To evaluate the expression process during the induction period in each test culture, a time course experiment was performed. The results showed that the expression of the fusion protein was linearly correlated with the time of induction. This showed that the expression of the fused product was continuously induced in each of the tested strains (Figure 4).

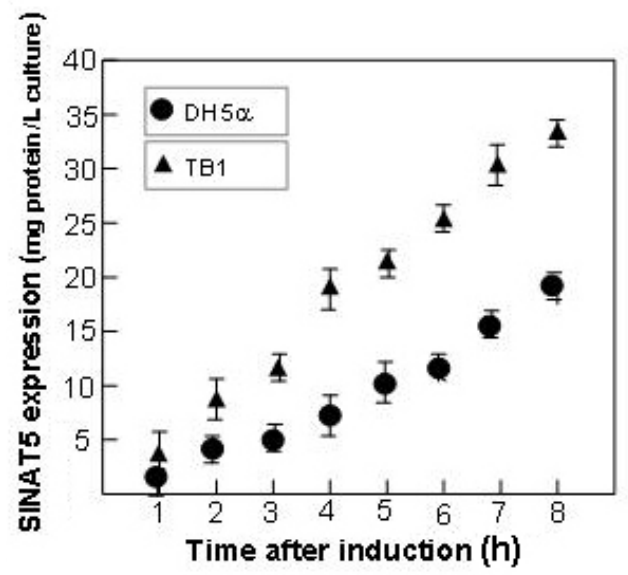

Figure 4. Expression of fused maize SINAT5 by the pMALc2X plasmid using Escherichia coli strains TB1 and DH5 $\alpha$ as host cells in the presence of $0.3 \mathrm{mM}$ IPTG (final concentration). The same experimental procedure was used for the expression studies in both test strains as it has been mentioned in Material and Methods section. A continuous and linear correlation is observed between the expression process and time of the induction in both $E$. coli strains. Data are reported as the means of three replicates. 
In a parallel experiment, the growth rates of both recombinant bacteria were evaluated under induced and non-induced conditions. The bacterial growth was assessed by measuring the absorbance of the cultures at $\mathrm{A}_{600}$ at 1-h time intervals. The results indicated that the growth of the bacteria was not affected by the induction of the fusion expression (Figure 5). This indicated that the expression of the maize SINAT5 protein had no inhibitory effects on the growth of E. coli cells.

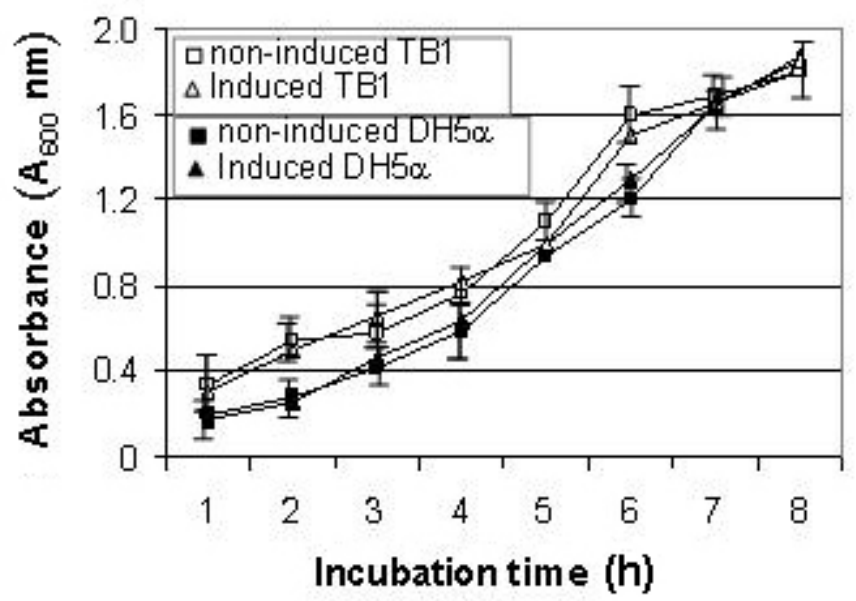

Figure 5. Bacterial growth patterns of the recombinant TB1 and DH5 $\alpha$ host cells. The cells were grown in Luria Bertani media under induced and non-induced conditions using the same experimental methods and the growth of bacteria was assessed by measuring the absorbance of cultures at $\mathrm{A}_{600} \mathrm{~nm}$. The similar growth patterns are observed in both test strains. Data are reported as the means of three replicates.

Comparison of the growth curves indicated no significant difference in the growth pattern of both test strains. This raised a question as to how the expression level of fusion product was affected in DH5 $\alpha$ cells. The continuous expression and similarity of growth curves suggested that under induced and non-induced conditions the expression of the fused product was not affected by the induction of the recombinant cells, but was continuously regulated during the growth of the bacteria. However, this continuous regulation might be different in the $2 E$. coli strains, resulting in the different expression patterns. Therefore, further studies are warranted to determine how the expression levels of the same fusion protein are altered in 2 different strains of $E$. coli cells when the same expression vector system and experimental conditions are used.

\section{ACKNOWLEDGMENTS}

Research supported by the Research Institute for Fundamental Sciences (RIFS), University of Tabriz, Tabriz, Iran.

\section{REFERENCES}

Alexandrov NN, Brover VV, Freidin S, Troukhan ME, et al. (2009). Insights into corn genes derived from large-scale cDNA sequencing. Plant Mol. Biol. 69: 179-194. 
Andersen DC and Krummen L (2002). Recombinant protein expression for therapeutic applications. Curr. Opin. Biotechnol. 13: 117-123.

Ausubel FM, Brent R, Kingston RE, Moore DD, et al. (1991). Current Protocols in Molecular Biology. John Wiley and Sons, New York.

Bachmair A, Novatchkova M, Potuschak T and Eisenhaber F (2001). Ubiquitylation in plants: a post-genomic look at a post-translational modification. Trends Plant Sci. 6: 463-470.

Bates PW and Vierstra RD (1999). UPL1 and 2, two $405 \mathrm{kDa}$ ubiquitin-protein ligases from Arabidopsis thaliana related to the HECT-domain protein family. Plant J. 20: 183-195.

Ciechanover A (1998). The ubiquitin-proteasome pathway: on protein death and cell life. EMBO J. 17: 7151-7160.

Downes BP, Stupar RM, Gingerich DJ and Vierstra RD (2003). The HECT ubiquitin-protein ligase (UPL) family in Arabidopsis: UPL3 has a specific role in trichome development. Plant J. 35: 729-742.

Freemont PS, Hanson IM and Trowsdale J (1991). A novel cysteine-rich sequence motif. Cell 64: 483-484.

Hellmann H and Estelle M (2002). Plant development: regulation by protein degradation. Science 297: 793-797.

Hershko A and Ciechanover A (1998). The ubiquitin system. Annu. Rev. Biochem. 67: 425-479.

Huibregtse JM, Scheffner M, Beaudenon S and Howley PM (1995). A family of proteins structurally and functionally related to the E6-AP ubiquitin-protein ligase. Proc. Natl. Acad. Sci. U. S. A. 92: 2563-2567.

Kandias NG, Chasapis CT, Bentrop D, Episkopou V, et al. (2009). High yield expression and NMR characterization of Arkadia E3 ubiquitin ligase RING-H2 finger domain. Biochem. Biophys. Res. Commun. 378: 498-502.

Kapust RB and Waugh DS (1999). Escherichia coli maltose-binding protein is uncommonly effective at promoting the solubility of polypeptides to which it is fused. Protein Sci. 8: 1668-1674.

Koegl M, Hoppe T, Schlenker S, Ulrich HD, et al. (1999). A novel ubiquitination factor, E4, is involved in multiubiquitin chain assembly. Cell 96: 635-644.

Kosarev P, Mayer KF and Hardtke CS (2002). Evaluation and classification of RING-finger domains encoded by the Arabidopsis genome. Genome Biol. 3: RESEARCH0016.

Laemmli UK (1970). Cleavage of structural proteins during the assembly of the head of bacteriophage T4. Nature 227: 680-685.

Lorick KL, Jensen JP, Fang S, Ong AM, et al. (1999). RING fingers mediate ubiquitin-conjugating enzyme (E2)-dependent ubiquitination. Proc. Natl. Acad. Sci. U. S. A. 96: 11364-11369.

Makrides SC (1996). Strategies for achieving high-level expression of genes in Escherichia coli. Microbiol. Rev. 60: 512-538.

Mazzucotelli E, Belloni S, Marone D, De Leonardis A, et al. (2006). The e3 ubiquitin ligase gene family in plants: regulation by degradation. Curr. Genomics 7: 509-522.

Moon J, Parry G and Estelle M (2004). The ubiquitin-proteasome pathway and plant development. Plant Cell 16: 31813195.

Pickart CM (2001). Mechanisms underlying ubiquitination. Annu. Rev. Biochem. 70: 503-533.

Schwechheimer C and Schwager K (2004). Regulated proteolysis and plant development. Plant Cell Rep. 23: 353-364.

Smalle J and Vierstra RD (2004). The ubiquitin 26S proteasome proteolytic pathway. Annu. Rev. Plant Biol. 55: 555-590.

Su L, Lineberry N, Huh Y, Soares L, et al. (2006). A novel E3 ubiquitin ligase substrate screen identifies Rho guanine dissociation inhibitor as a substrate of gene related to anergy in lymphocytes. J. Immunol. 177: 7559-7566.

Terpe K (2006). Overview of bacterial expression systems for heterologous protein production: from molecular and biochemical fundamentals to commercial systems. Appl. Microbiol. Biotechnol. 72: 211-222.

Xie Q, Guo HS, Dallman G, Fang S, et al. (2002). SINAT5 promotes ubiquitin-related degradation of NAC1 to attenuate auxin signals. Nature 419: 167-170. 